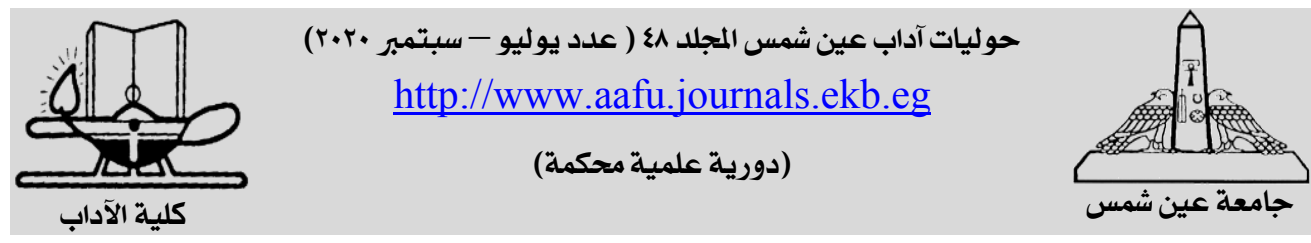

\title{
التناص من منظور ابن طباطبا العلوي
}

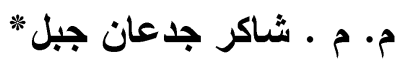

جامعة بغداد - كلية العلوم الاسلامية

الإنtion

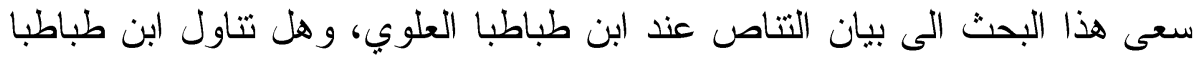

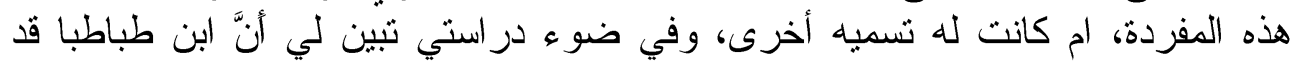

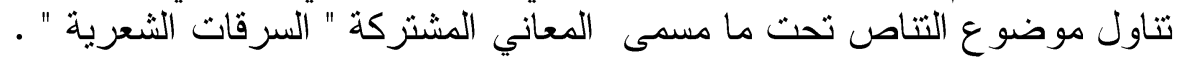




\section{المقدمــة}

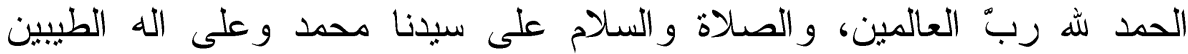

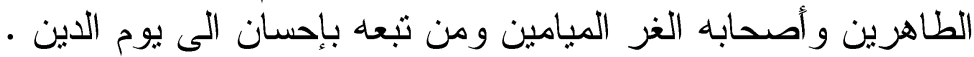
وبعد ب...

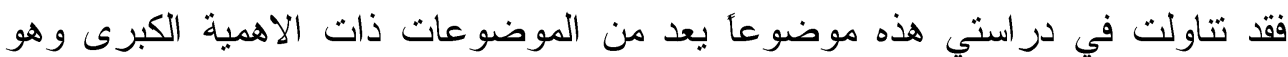

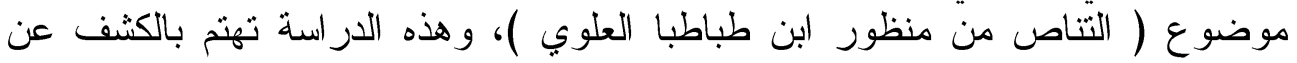

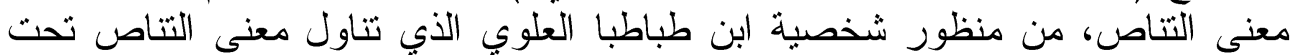

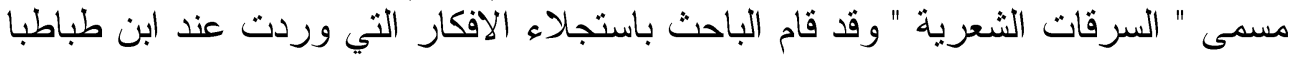

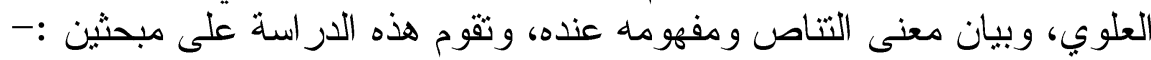

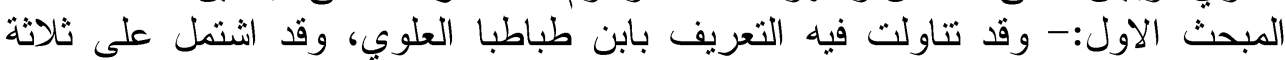

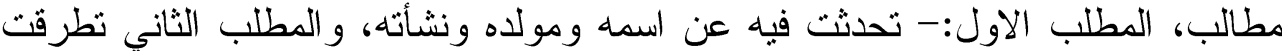

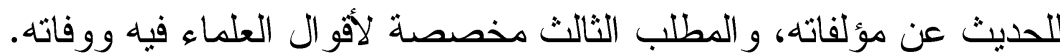

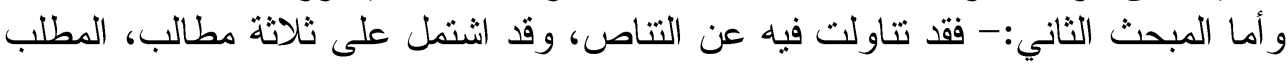

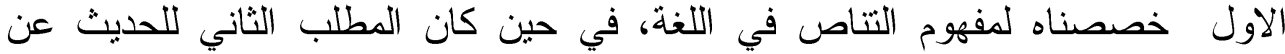
التتاص في الاصطلاح، و المطلب الثنالث تناولت فيه التتاص من منظور ابن طباطبا

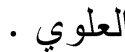
ثم جاءت الخاتمة وقد أوجزتُ فيها اهم النتائج التي تمخض عنها البحث.

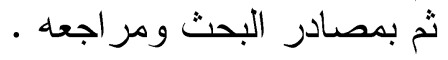




\section{المبحث الاول \\ التعريف بان طباطبا العلوي \\ المطلب الاول :- اسمه وولادته ونشأته}

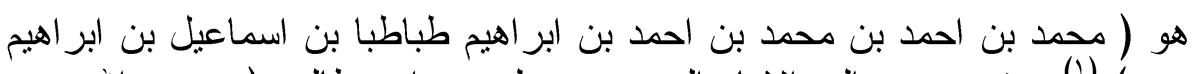

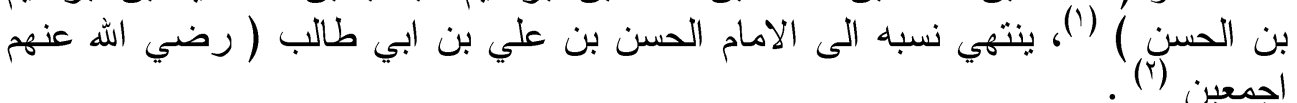

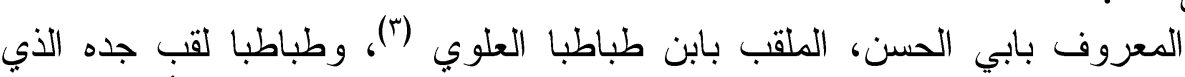

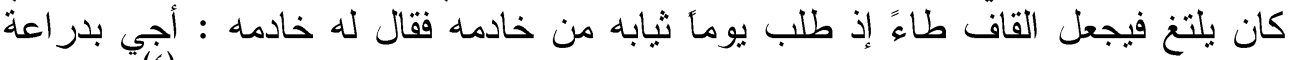

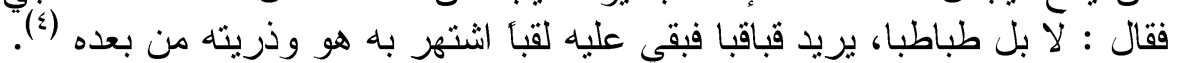

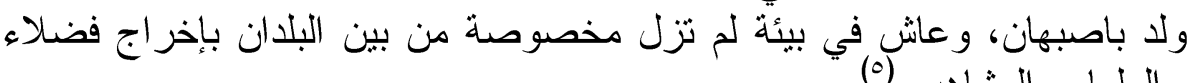

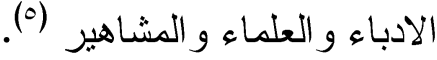
وهو شاعر مفلق وعالم محقق، اشتهر بالفطنة و الذكاء وصفاء القريحة، وصحة

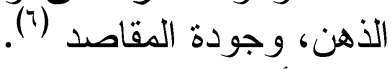

أي في نهاية القرن الثالث وبداية القرن الرابع من الهجرة، في مدة حرجة تأرجت

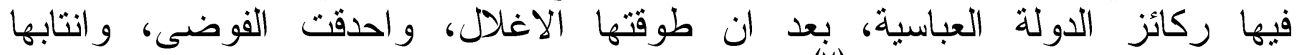

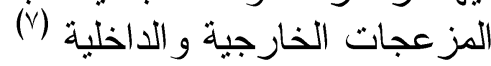

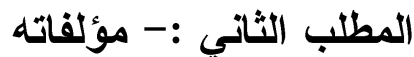
لابن طباطبا العلوي عدة مؤلفات منها : الماته

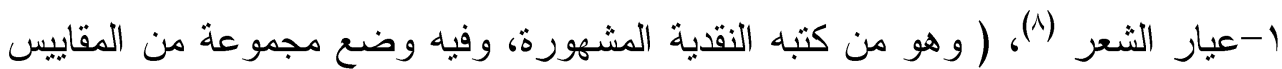

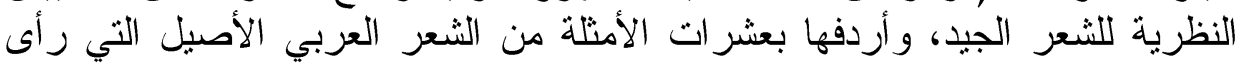
انها تحقق هذه المقاييس، وكذللك اورد أمنلة للأشعار التي تخرج عن عن هذه المقايبي،

و وأشهر ما في الكتاب مقدمته النقدية ) (9) النقايبن

$$
\begin{aligned}
& \text { r- ب-تهذيب الطبع }
\end{aligned}
$$

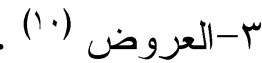

$$
\begin{aligned}
& \text { ع-كتاب سنام المعالي } \\
& \text { ه-كتاب الثعر و الثشعر اء ('1') } \\
& \text { צ-المدخل في معرفة المعمى من الثعر }
\end{aligned}
$$

المطلب الثالث :- اقوال العلماء الثماء فيه ووفاته

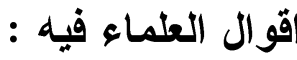

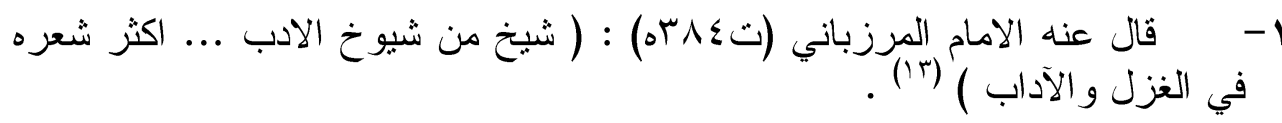

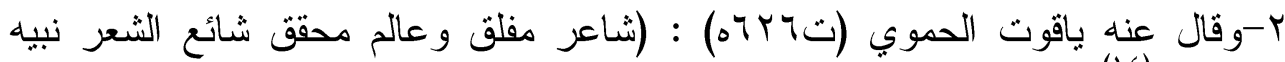

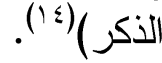


ب-وقال عنه عمر فروخ : ( كان ابو الحسن محمد بن طباطبا العلوي شاعراً وناقدأ

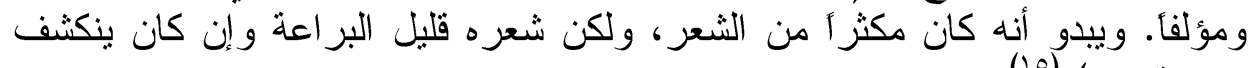

$$
\begin{aligned}
& \text { عن مقدره ) (10) } \\
& \text { وفاته : ونغ }
\end{aligned}
$$

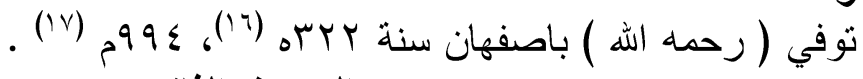

$$
\begin{aligned}
& \text { المبحث الثاني } \\
& \text { التناص من منظور ابن طباطبا }
\end{aligned}
$$

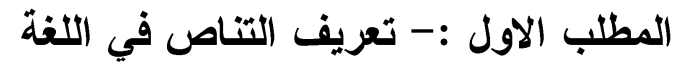

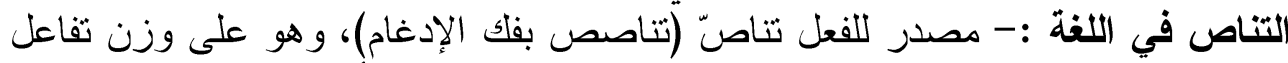

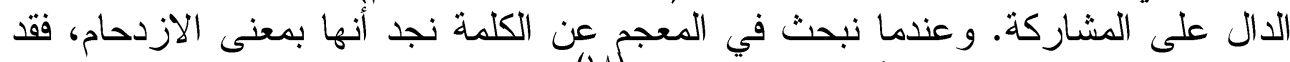

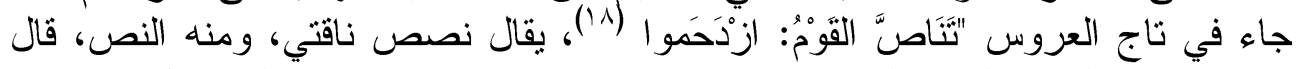

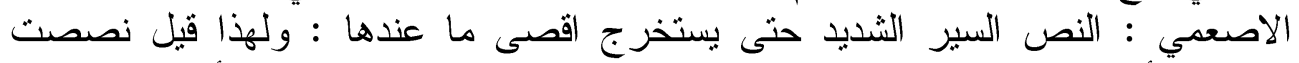

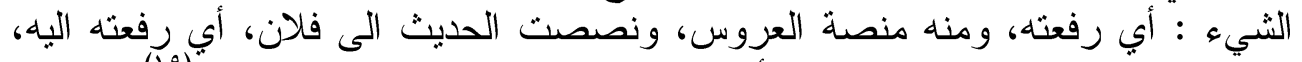

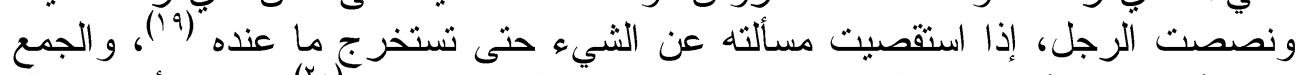

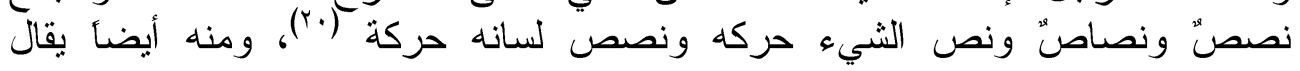

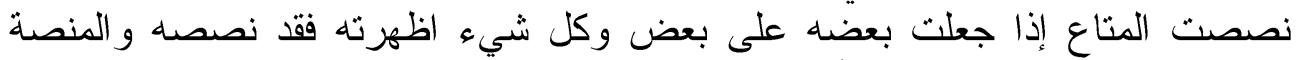

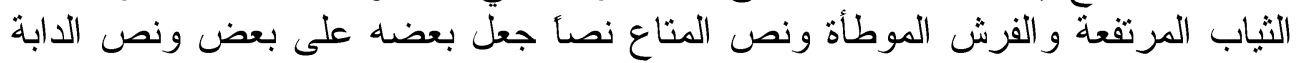

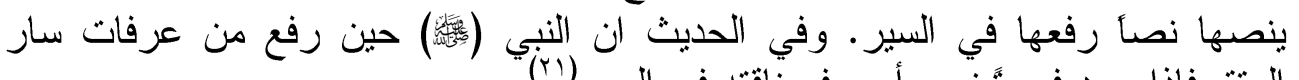

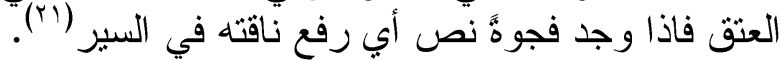

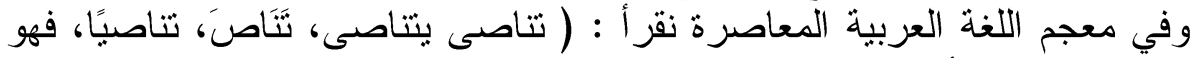

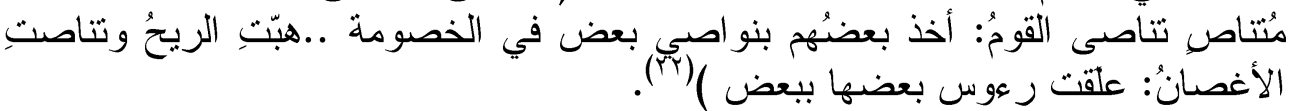

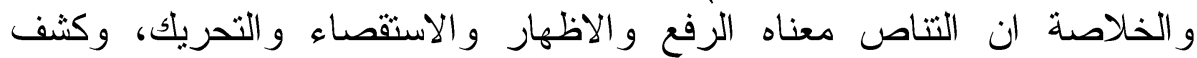

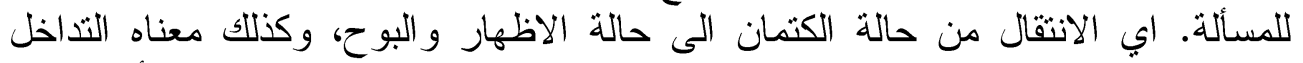

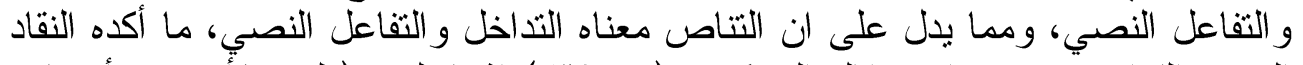

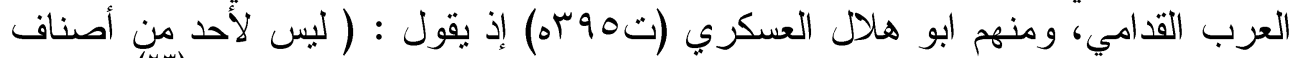

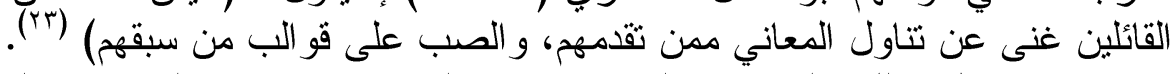

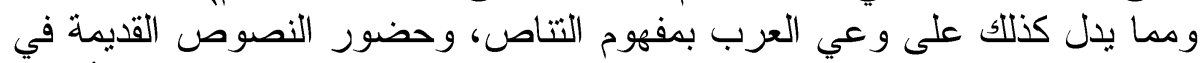

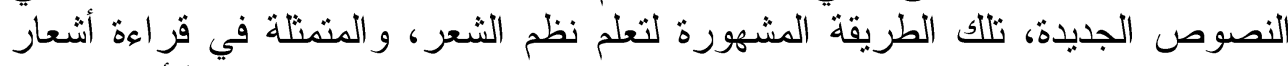

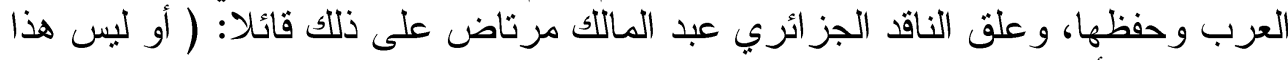

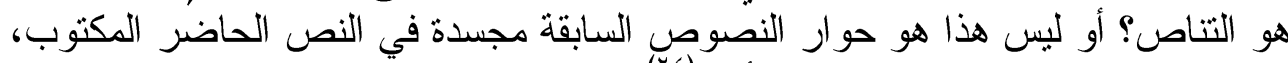

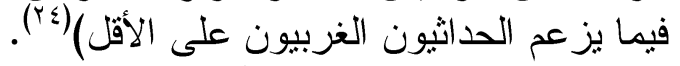

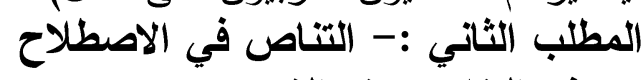
تعريف التناص عند الغربيين

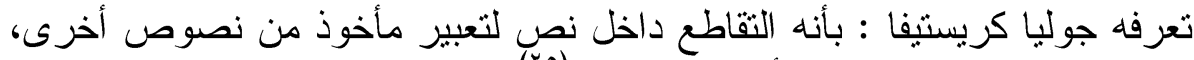

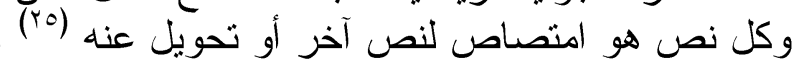

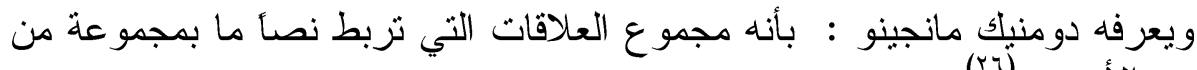

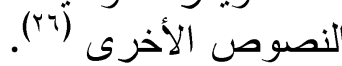
مما تقدم يتبين لنا ان التتاص عند الغربيين معناه تداخل نص مع نصوص أخرى 


\section{تعريف التناص عند النفاد العرب القدامى والمعاصرين} اختلف النقاد العرب في تعريف التناص

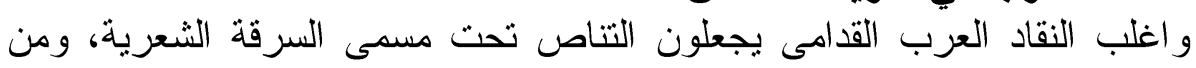

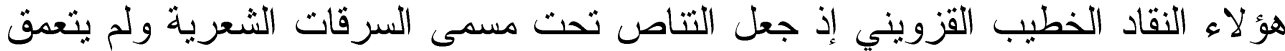

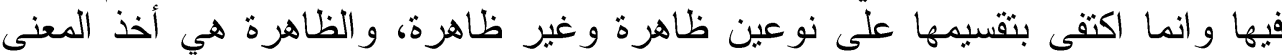

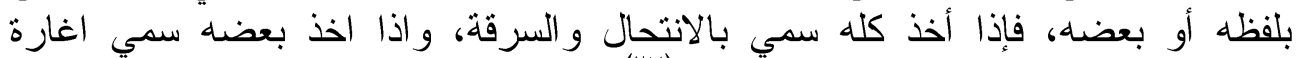

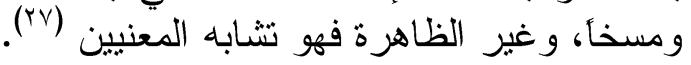
اما التناص عند النقاد العرب المعاصرين

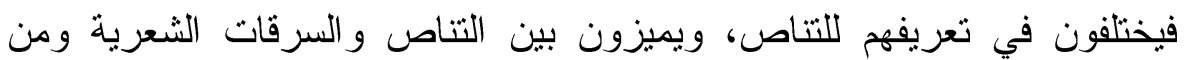

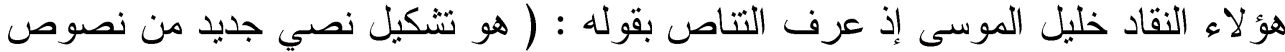

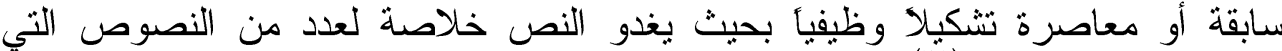

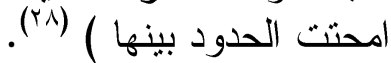
و هو بهذا يفرق بين التناص وبعض المفاهيم فيقول : ( التتاص غير التضمين

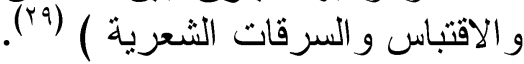

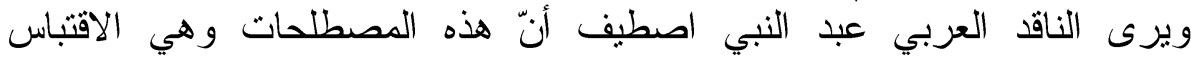

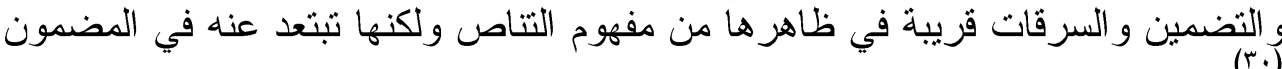

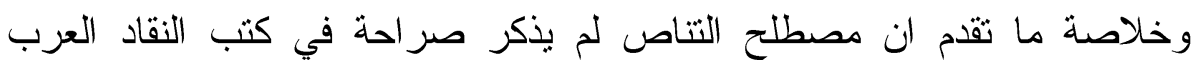

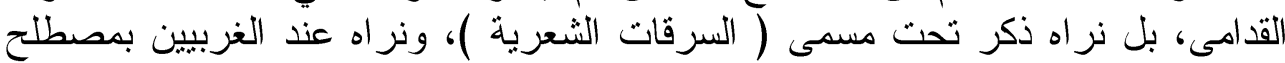

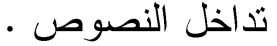

المطلب الثالث :- التناص من منظور ابن طباطبا العلوي

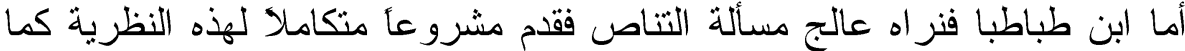

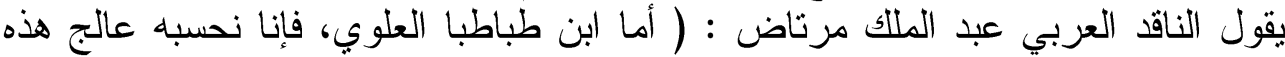

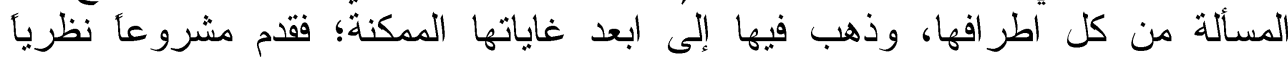
متكاملا لنظرية التناص. وكان هذا المنظر من الوعي المعرفي ما بمكن ان بحمل البران الباحث

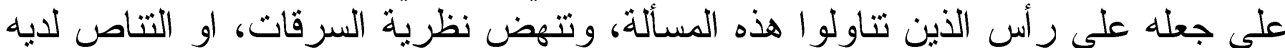

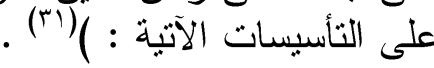

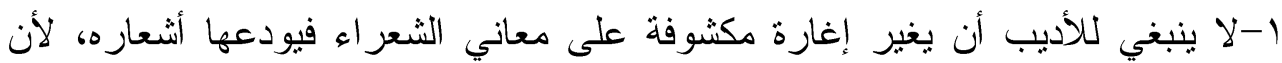

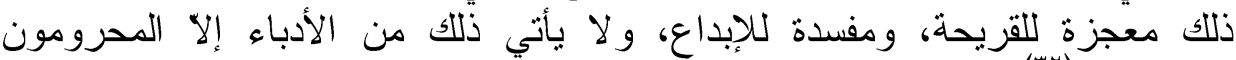

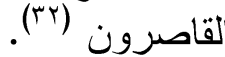

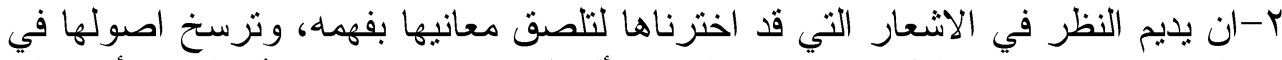

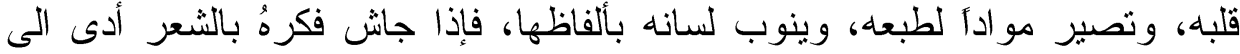

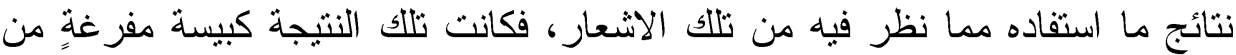

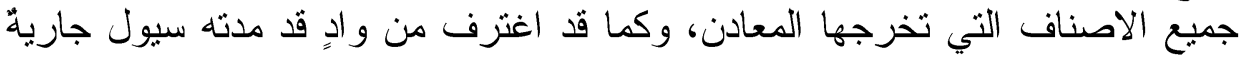

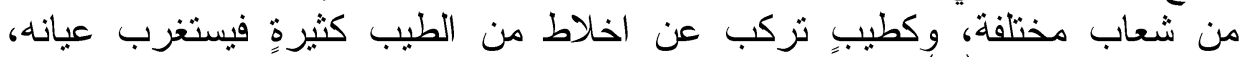
ويغمض مستتبطه (r) منعاب)

وبهذا نلاحظ ان ابن طباطبا العلوي يقدم ثلاثة أمثلة للتناص، و لا يجتزى بمثال

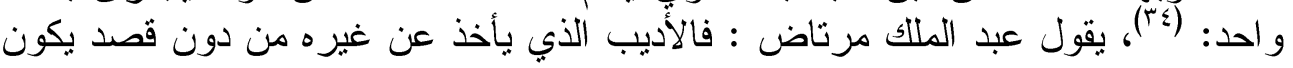


أ- كسبيكة مفرغة من جميع الأصناف التي تخرجها المعادن، ولناحظ ان جسما و احدأ

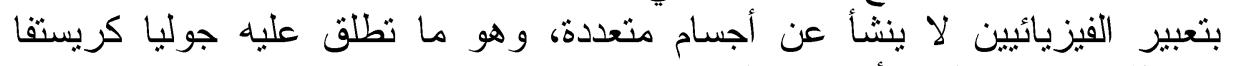

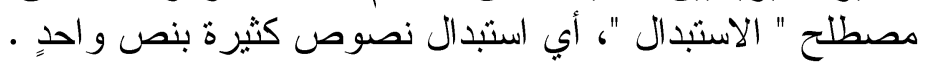

ب- (وكما اغترف من و ادٍ قد مدته سيول جاريةٌ من شعاب مختلفة، فالسيول الجارية

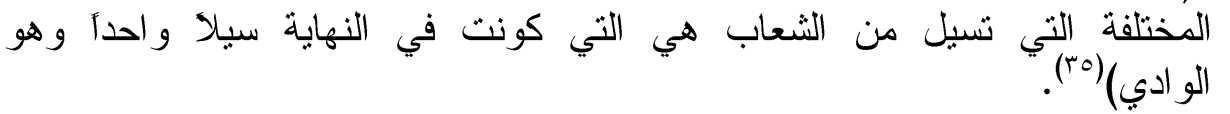

ج- (وكطيبٍ نركب عن اخلاطٍٍ من الطيب كثيرة، فيستغرب عيانه ويغمض مستتبطه)

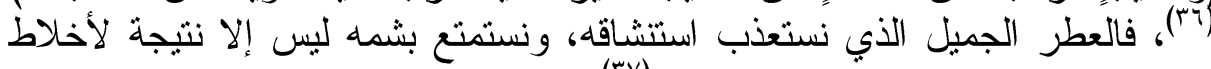

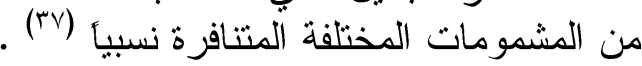

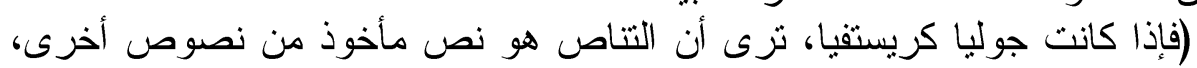

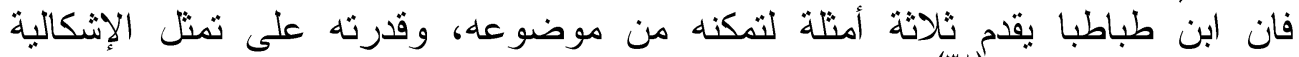

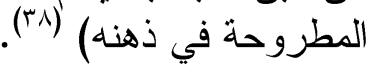
r- ويدعم ابن طباطبا نظريته بتجربه عملية كان قد نهض لها لها عبداله القسري أحد أكبر

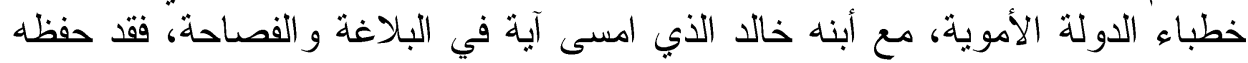

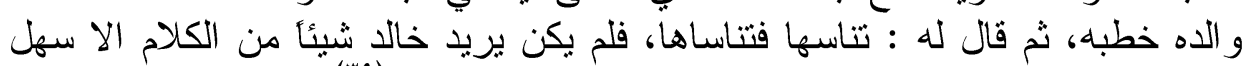

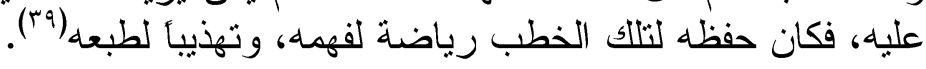

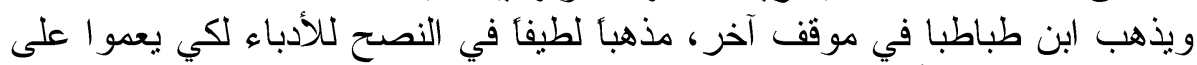

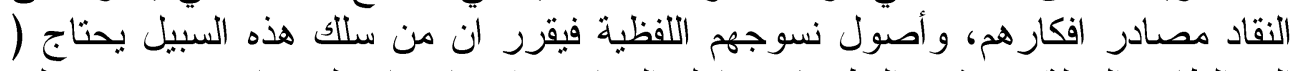

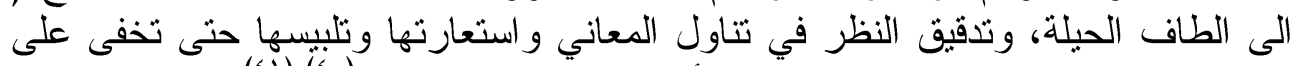

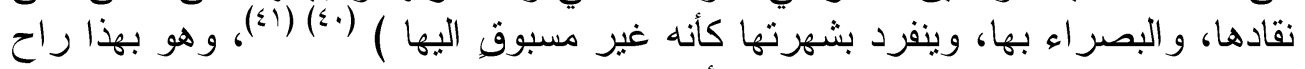

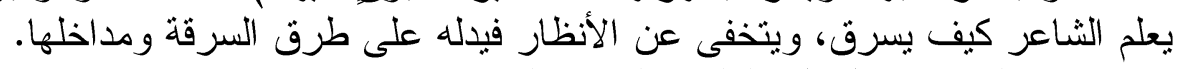

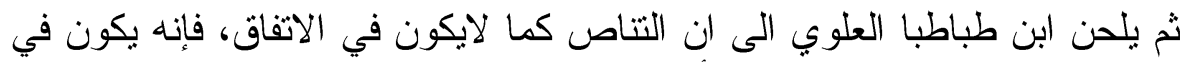

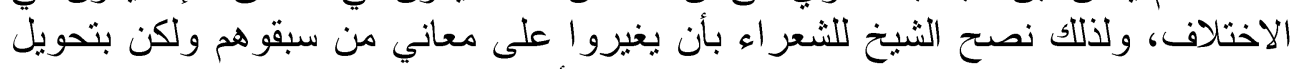

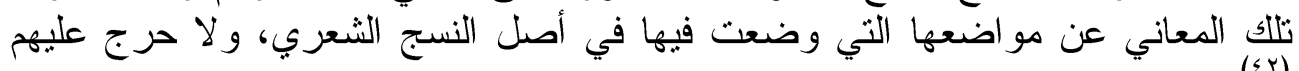

لذلك كان ابن طباطبا رحب الصدر فيما يتصل بسرقة المعاني إذ يقول : (و إذا لإبان

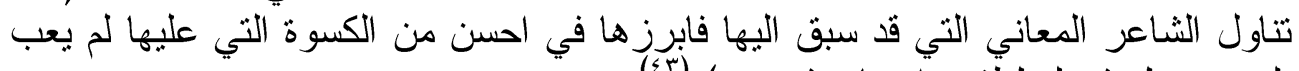

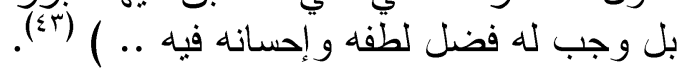

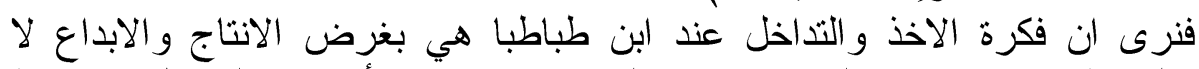

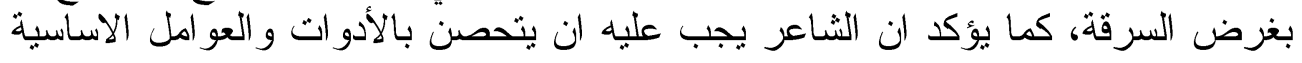

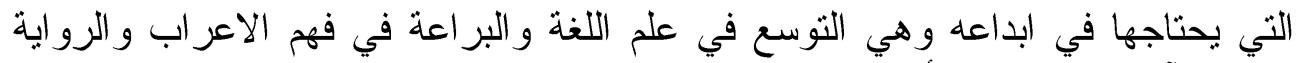

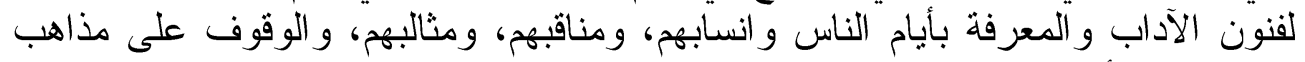

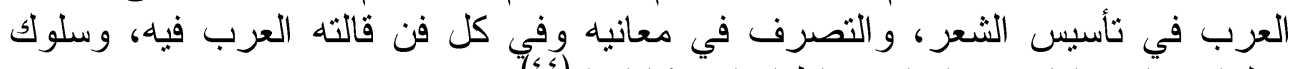

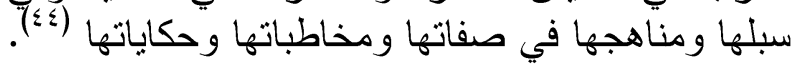

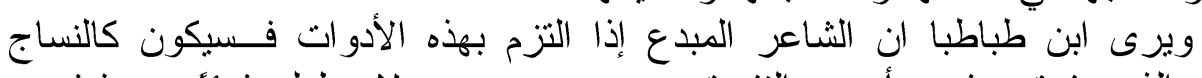

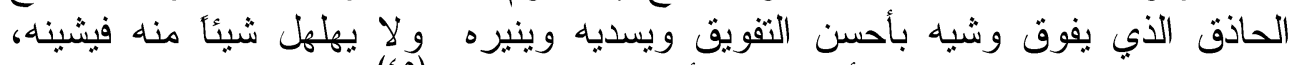

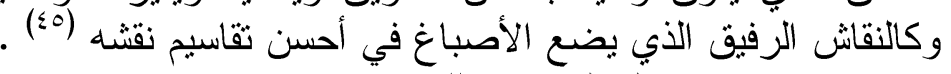

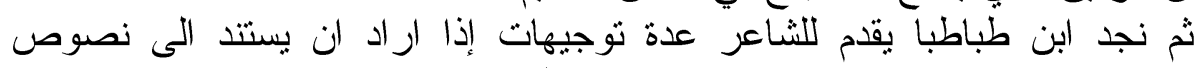

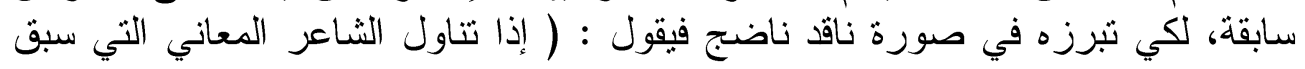


إليها فابرزاز ها في أحسن من الكسوة التي عليها لم يعب، بل وجب لهن له فضل لطفه و إحسانه

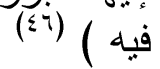

ويؤمن ابن طباطبا ان اشعار الثعر اء كلها منقاربة سو اء من قريب او بعيد فيقول :

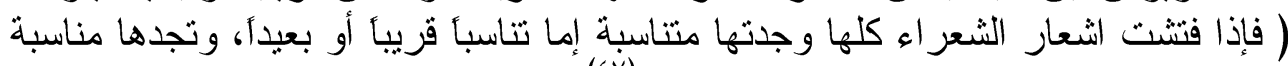

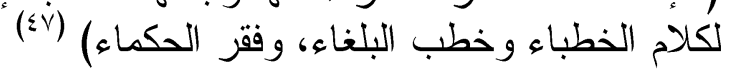

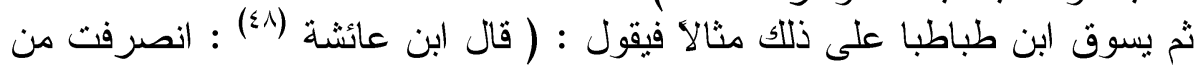

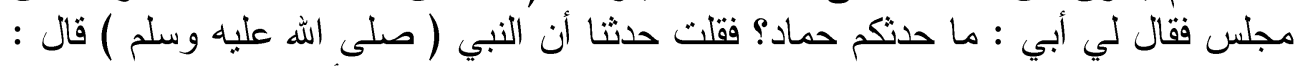
لو لم يلف ابن ادم الا على الصحة و السلامة لكفى بهما داءً . فقال أبي : قاتل الله حميد بن اله

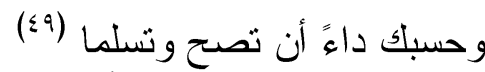

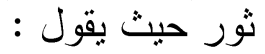

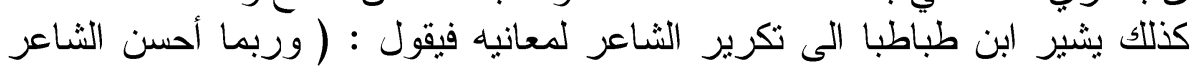

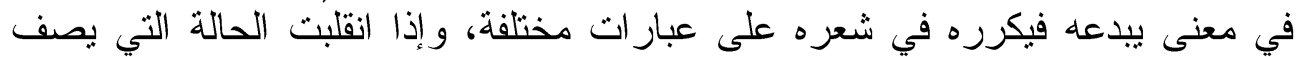

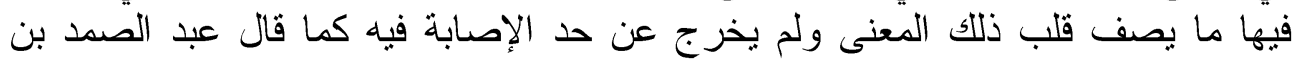

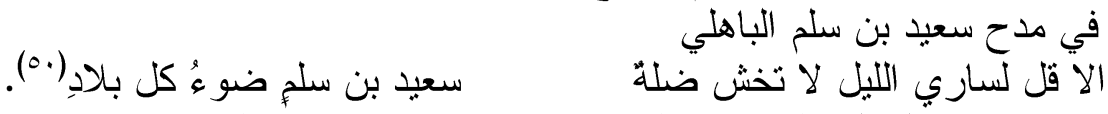

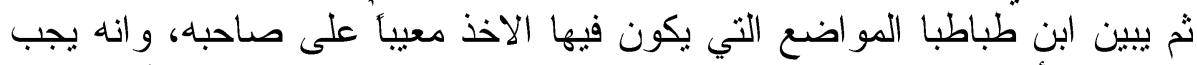

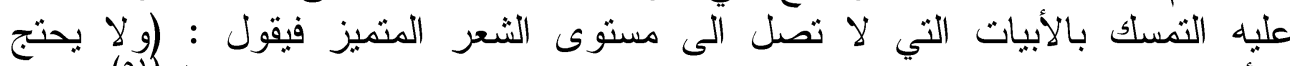

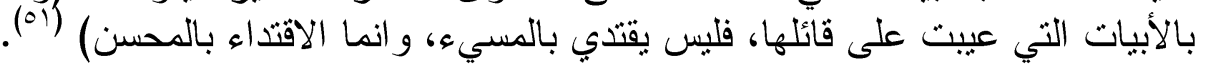

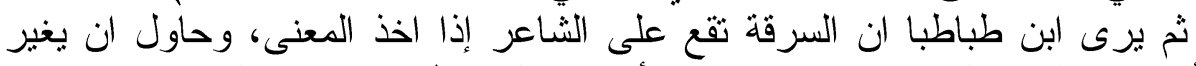

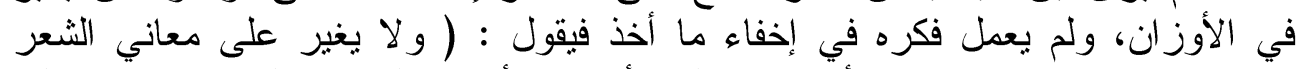

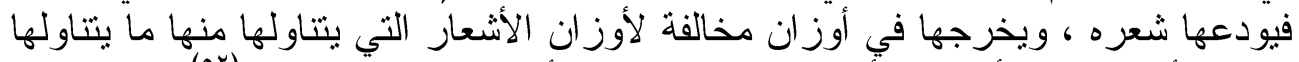

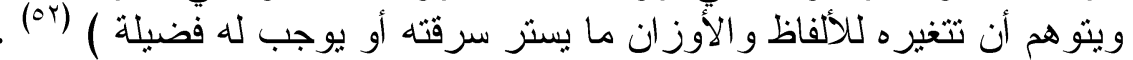

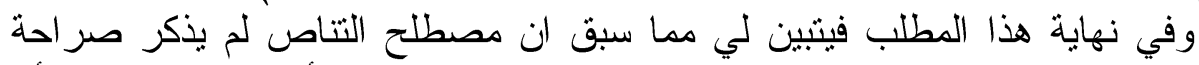

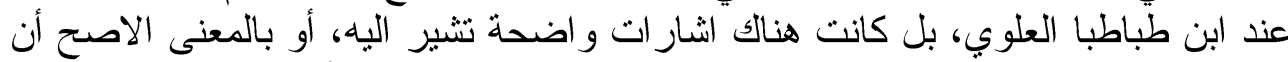

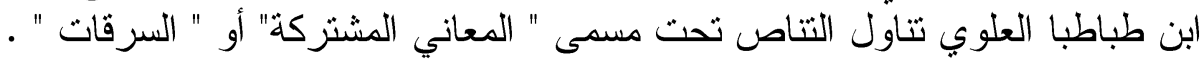




\section{الخاتمـــة}

وفي النهاية، فان خير الكلام ما قل ودل وخير العمل ما حسن أخره .

فبعد دراستي لبحثي الموسوم بـ ( التناص من منظور ابن طباطبا العلوي ) فقد

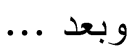

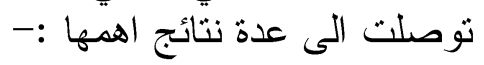

1- لم نجد عند ابن طباطبا العلوي ما بسمى بالتتاص و إنما ذكره نحت ما يمسى بالسرقة

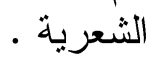

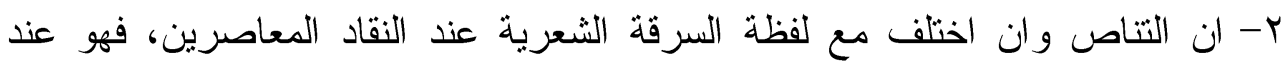

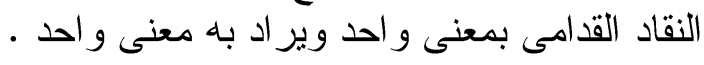

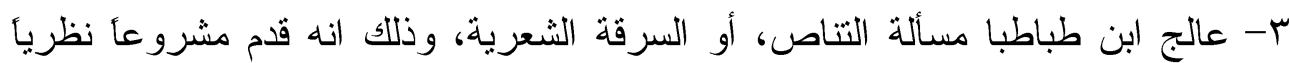

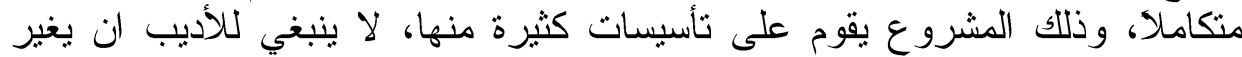

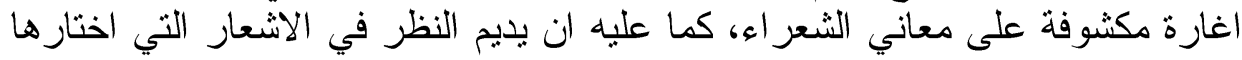
النقاد لتلصف معانيها بفهمة.

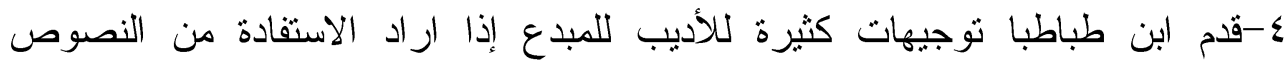

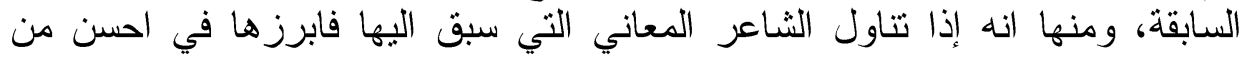

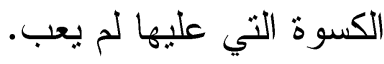

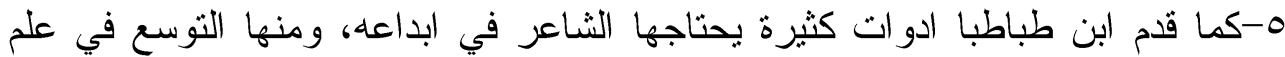

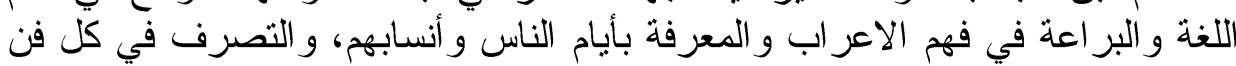

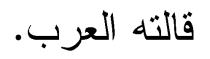




\section{Abstract \\ From the perspective of Ibn Tabtaba laloui \\ By Shaker Jad'aan Mount}

This research sought to intertextuality statement Ibn Tabataba top, whether I'm eating Tabataba this single, or they have other calls, and in the light of my study I show that the son of Tabataba had addressed the subject of intertextuality under the name of common meanings "thefts of poetry.

الأهوامش

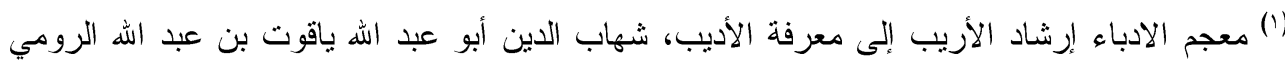

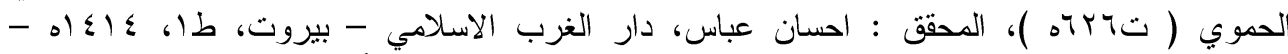

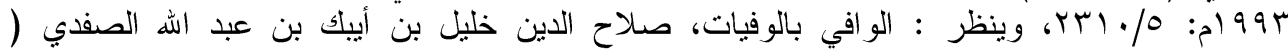

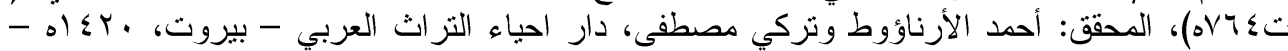

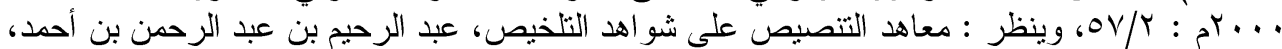

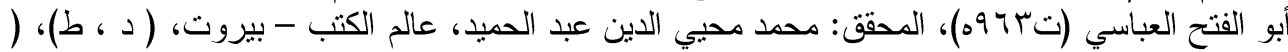

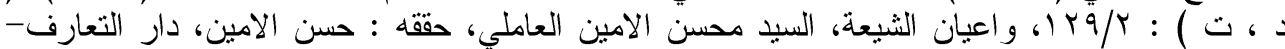

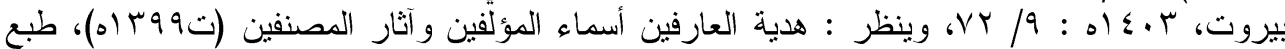

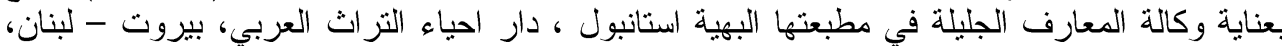
. L

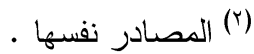

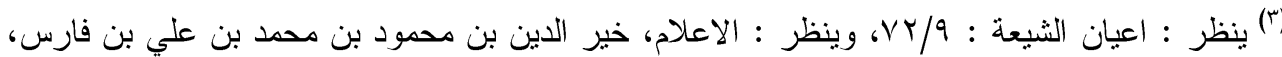

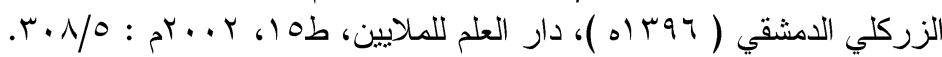

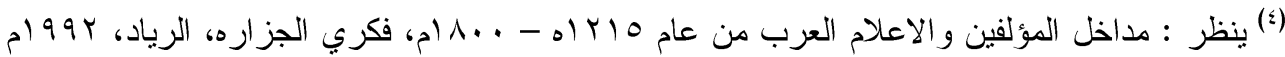
. $111-V 9 / \mathrm{r}:$

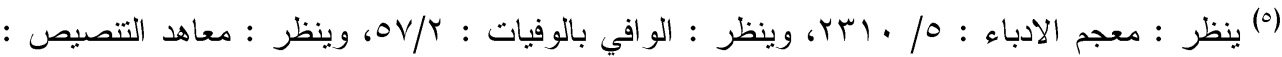

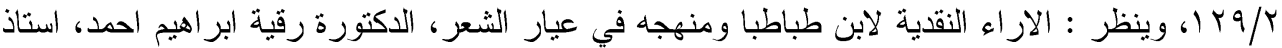

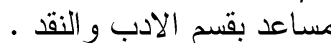

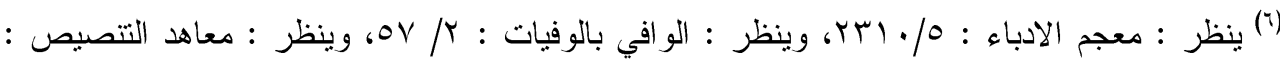
$.1 r \cdot / r$

(l) ينظر : عبار الشعر لابن طباطبا العلوي، بقلم : عبد القادر الشيخ إدريس، مجلة الفيصل، العدد (.0) :

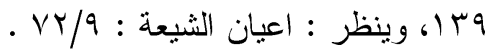

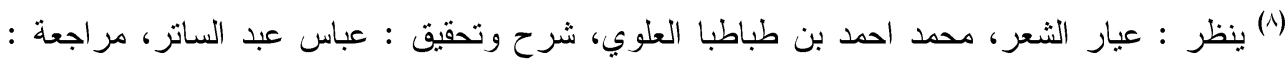

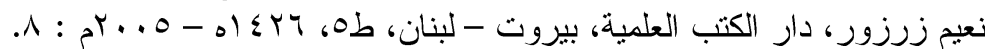

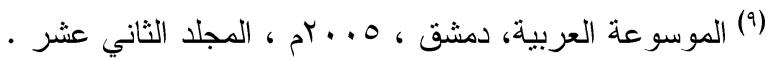

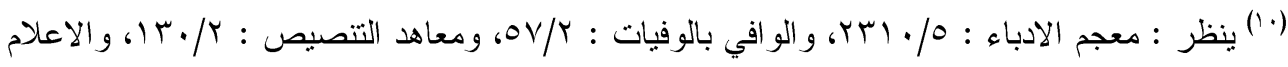
r. N/0:

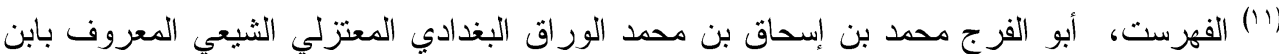

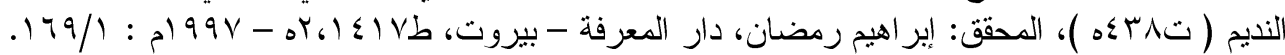

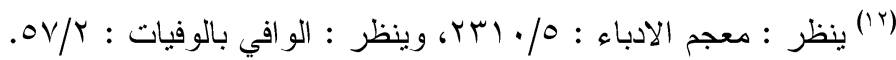




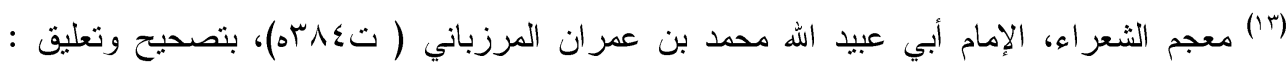

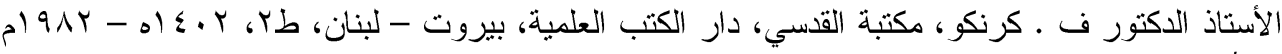

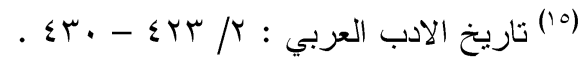

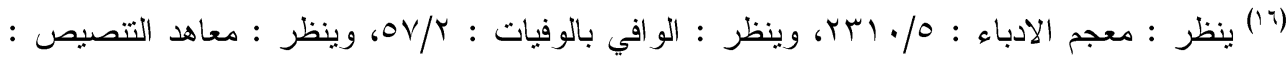

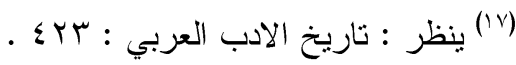

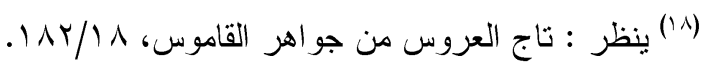

(9)" ينظر : الصحاح تاج اللغة وصحاح العربية، ابو نصر اسماعيل بن حماد الجوهري (تبروسه)،

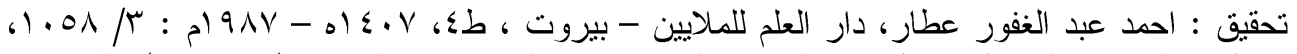

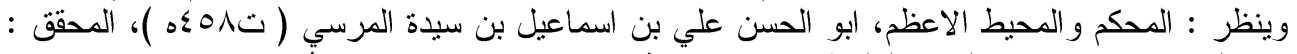

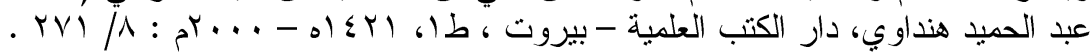

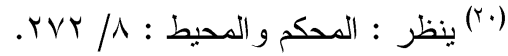

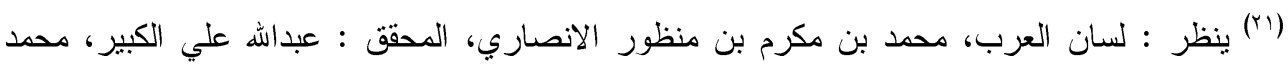

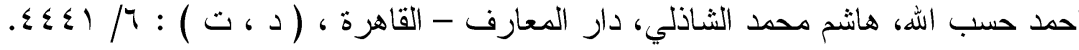

(Yr)

('rr) الصناعتين، ابو هلال العسكري، تحقيق : علي البجاوي ومحمد ابو الفضل ابر اهيم، المكتبة العصرية - TIV: بيروت،

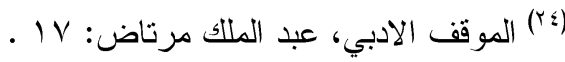

(ro) التتاصية و النقد الجديد، ليون سومغي، ترجمة : و ائل بركات، مجلة علامات، السعودية - جدة،

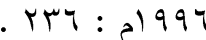

(تبا) التتاص في الثعر العربي الحديث، البرغوثي انموذجأ، حصة البادي، دار كنوز المعرفة ، طا،

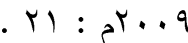

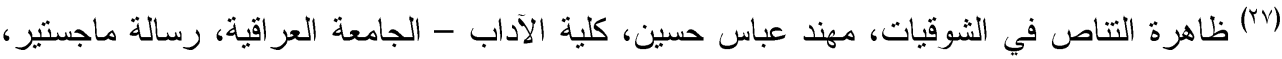
. 2.0 .11

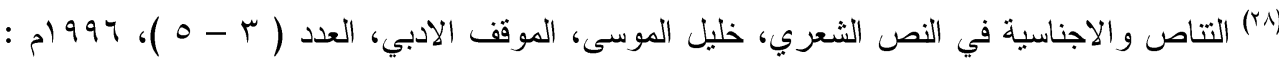

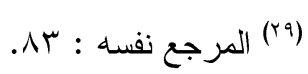

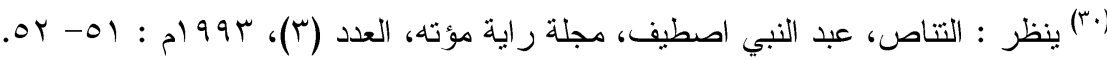

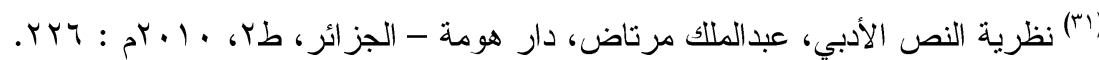

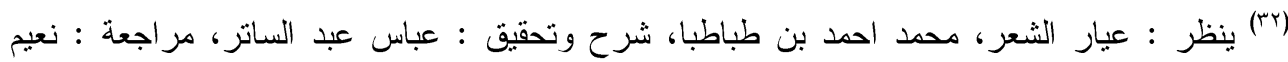

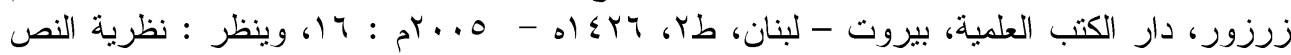
الأدبي : ز ينظر : (r)

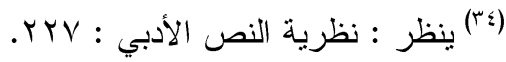




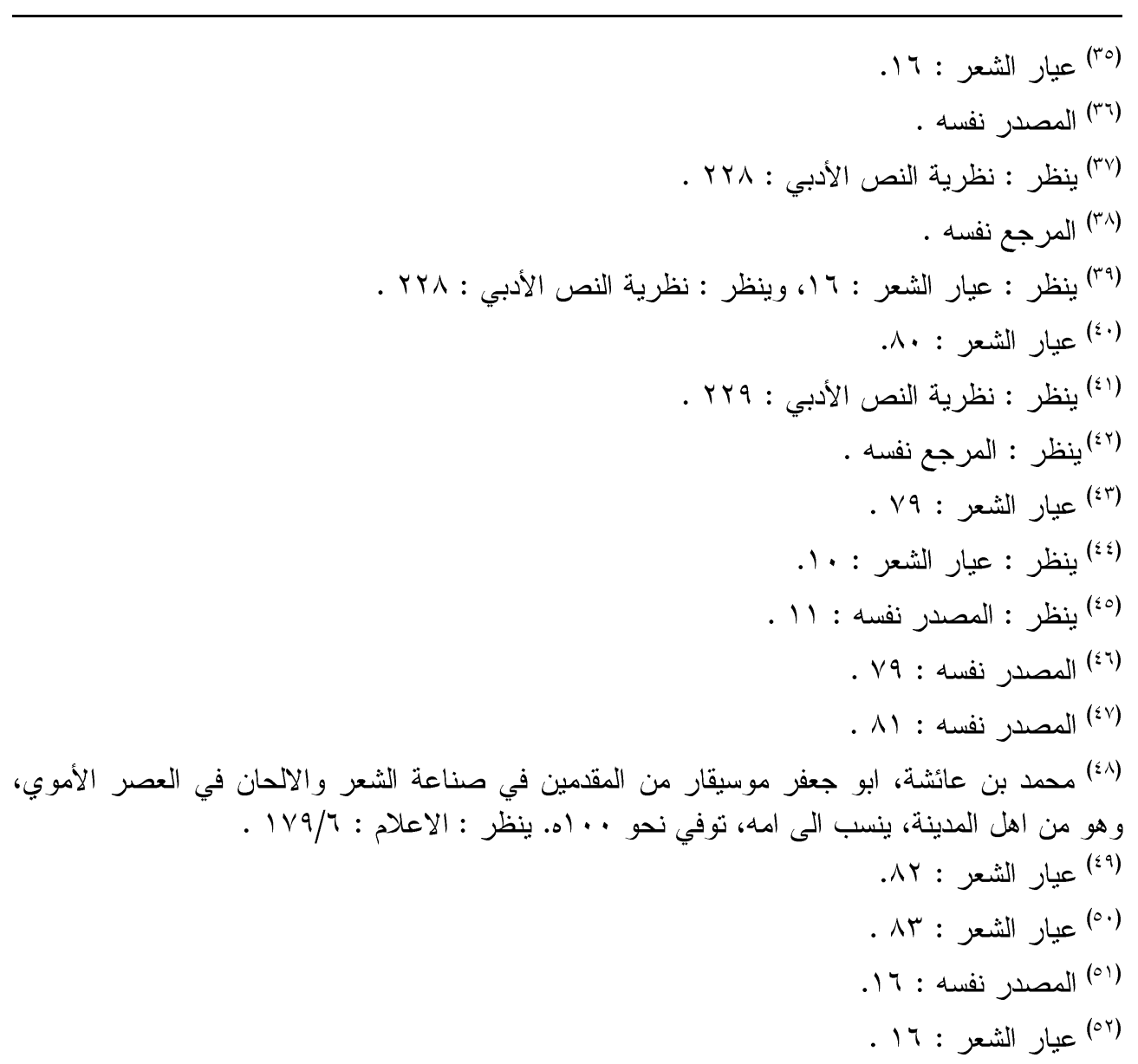

